poietin, its bioassay and standardization, precede general chapters on erythropoietin physiology and mode of action, and there is a useful section on non-erythropoietin dependent erythropoiesis. Foetal and neonatal erythropoiesis is examined in terms of differences in control between prenatal and adult animals, and the occurrence and significance of foetal haemoglobins. Prenatal erythropoiesis also receives considerable attention in a valuable chapter on genetic abnormalities of erythropoiesis in mice. Discussion of clinical derangements of human erythropoiesis due to mutant genes receives minimal attention, however, although there is a chapter on polycythaemia. Biochemical aspects of erythropoiesis are summarized in chapters on regulation of iron metabolism, role of transferrin, and haem and globin synthesis.

The second volume is devoted entirely to white cell and platelet production. The ultrastructure of developing, normal and diseased granulocytes is discussed in two introductory chapters, and there is also a discussion of kinetic analysis of normal granulocyte production and release. Morphological aspects and kinetics of neutrophil and eosinophil production and mobilization receive detailed attention in four chapters. Sections on metabolism of resting and phagocytosing leucocytes provide the physiological background for discussions of the role of leucocytes in inflammation and immunology, including their passage through blood vessel walls, and subsequent migration. Various aspects of lymphocyte production are dealt with in detail, beginning with the ultrastructure of lymphocytes and their development. Discussions of the regulation and kinetics of lymphocyte differentiation in vivo and in vitro complement structural and functional descriptions of the lymph node and lympho-myeloid complex and their role in the immune response. Abnormalities of white cell proliferation are discussed in chapters dealing with the value of experimental leukaemias, kinetics and biochemistry of leukaemic leucocytes and lymphocytes, and the immuno-proliferative disorders. Ultrastructural and physiological aspects of platelet production in three chapters complete this volume.

In general the editor has succeeded in integrating some thirty articles in each volume into a coherent treatise. Both are illustrated to a high standard, including many photomicrographs. Inevitably, in a work of this scope it is possible to fault the relative attention given to different topics. Perhaps, most seriously, in Volume I recent advances in understanding the regulation of haemoglobin synthesis at the molecular level receive little attention, and, in Volume II, there is little discussion of the role viruses may play in abnormal cell proliferation. Extensive reference lists follow each chapter, and are a valuable feature of both volumes, but there is no overall author index, and the subject indices are disappointingly inadequate.

These books will be of great value to experimental haematologists in relating their data to a coherent view of haematopoietic regulation, and the editor's hope that his labours will stimulate further research is likely to be fulfilled.

R. J. COLE

\section{Lymph and Lymphocytes}

Lymphatics, Lymph and the Lymphomyeloid Complex. By Joseph Mendel Yoffrey and Frederick Colin Courtice. Pp. xviii +942. (Academic: London and New York, November 1970.) £12.50; $\$ 35$.

THIs is a new book which has succeeded two previous editions on the same subject with a similar name, Lymphatics, Lymph and Lymphoid Tissue. The principal advances in this subject, however, have necessitated a new text with rather different emphasis. The book is very large and comprehensive and is an attempt to unify as a system the lymphocytes and their source of origin and their lymphatic vessels. The result is a very long book ranging through many different subjects. The embryology of lymphatics is discussed together with the physiology of lymph flow and the composition of lymph. Comparative aspects in vertebrates are considered together with lymph vessels for each individual organ. There are sections on radiology, and pathology of lymphatics; particularly the results of infection and tumour.

The lymphocyte is discussed from all points of view, namely, morphology, movement, enzyme production, response to mitogens and the relationship of the lymphocyte to the macrophage. The lymph node is similarly treated from a morphological and functional point of view and the immunological changes that occur in relation to antigenic stimulation and homotransplantation are illustrated. There are chapters on lymphocyte production and lymphocyte migration and the relationship of the thymus to the rest of the lymphatic system. There is a final section on laboratory technique in determination of cell viability, lymphocyte culture, production of lymphocyte suspensions and cell transfusion, and the shielding of lymphocytes from damage of irradiation.

The book is an excellent work of reference. The bibliography, if not comprehensive, is certainly adequate and it is easy to find references, for they are recorded both in chapters and at the end of the book in an author index. The work represents immense effort of scholarship and will be an essential volume in all laboratories undertaking biological research. My only criticism would be that with such a wide scope, individual subjects cannot possibly be dealt with in great detail, but this is not presumably the objective of the text which is more in the form of a review and, as such, can be confidently recommended.

R. Y. CALNE

\section{Continents Adrift}

Continental Drift: A Study of the Earth's Moving Surface. By D. H. Tarling and M. P. Tarling. Pp. $112+4$ plates. (Bell: London, February 1971.) £1.50.

ANYONE who chooses to write a popular account of continental drift, sea floor spreading, plate tectonics and similar topics variously lumped together these days as the "new global tectonics" must face up to a problem. There is already one book covering this ground at a similar level ${ }^{1}$ - and a book, moreover, to which so many superlatives have been applied in review that the adman's view of the latest Hollywood epic looks pale by comparison. None of this would matter too much, of course, were the praises sung to Takeuchi et al. misplaced. But they were not. The result is that the Tarlings are attempting to surpass a feat which is wellnigh insurpassable and which will almost certainly not be surpassed for many a year to come.

That the Tarlings have not quite succeeded in this should not worry them too much, however. The comparison is reasonable and even inevitable; but it is also possible to judge a book on its own merits. To say that Brahms did not quite surpass Beethoven is not to suggest that the former is not worth an audience. In fact, the Tarlings have produced a rather good survey of our present view of the Earth as a dynamic body. Beginning with the prophets of continental drift they take us through the evidence from geometry (the "continental jigsaw"), the Earth's crust (the "picture on the jigsaw"), ancient environments and climates, and palaeomagnetism to sea floor spreading and plate tectonics. The final three chapters then deal with the timing, causes and significance of the drift phenomenon.

If I have any misgivings at all, it is just that the Tarlings have a slight tendency to oversimplify and perhaps even overdramatize. The idea that Francis Bacon first spotted the congruency between the west coast of Africa and the east coast of South America makes a fascinating little story but owes more to myth than reality. More seriously perhaps, surely it is misleadingly optimistic to suggest that "in the very near future it should be possible to control many earthquakes"? The Joadian response to the very near future hardly covers that one. But these are small points. The book as a whole rates five stars. PETER J. SMITH

1 Takeuchi, H., Uyeda, S., and Kanamori, H., Debate About the Earth (Freeman, Cooper, San Francisco, 1967, revised edition 1970.) 